\title{
Homologous bacterio-opsin-encoding gene expression via site-specific vector integration
}

(Halobacterium halobium; archaebacteria; shuttle-mutagenesis vector; transformation; ISH element; genomic integration; bat; brp; bop)

\author{
E. Ferrando, U. Schweiger and D. Oesterhelt
}

Max-Planck-Institut für Biochemie, D-8033 Martinsried, Germany

\section{SUMMARY}

Homologous recombination in the archaebacterium Halobacterium halobium has been investigated and exploited for the wild-type (wt) level of expression of the bacterio-opsin-encoding gene (bop). The Haloferax volcanii-Escherichia coli shuttle vector, pWL102, was used to construct a shuttle-mutagenesis vector, pEF191, bearing bop and short flanking sequences. Transformation of a bacteriorhodopsin (BR)-negative $H$. halobium strain with pEF191 resulted in plasmid integration at the homologous bop locus. A model for this site-specific vector integration is presented which has been confirmed by determining the arrangement of the repeated homologous sequences on the chromosome. Two different configurations are obtained after integrative transformation due to the presence of an insertion element in the genomic copy of bop. In one configuration, the functional bop cluster containing the regulatory bat and brp genes was in wt arrangement. In the second configuration, the bop cluster is interrupted by $10 \mathrm{~kb}$ of plasmid vector sequences, and the upstream region required for bop expression was limited to $400 \mathrm{bp}$. The BR production for both configurations was determined and found to be at wt level. These results suggest that the function of the putative bop promoter does not depend on the defined upstream positions of bat and $b r p$. The system presented here can be easily exploited for structurefunction studies on BR and introduces homologous gene targeting as a powerful tool in the study of halobacterial genetics.

\section{INTRODUCTION}

The seven-helix motif is a structural feature characteristic of the family of eukaryotic rhodopsins. In the prokary-

Correspondence to: Dr. E. Ferrando, Max-Planck-Institut für Biochemie, Am Klopferspitz 18a, D-8033 Martinsried, Germany. Tel. (49-89)8578-2476; Fax (49-89)8578-3557.

Abbreviations: Ap, ampicillin; bat, gene encoding the putative BR-activating protein; bop, gene encoding bacterio-opsin; bp, base pair(s); BR, bacteriorhodopsin; brp, gene encoding the putative BR-related protein; cpm. counts per minute; $\Delta$, deletion; EtdBr, ethidium bromide; H., Halobacterium; Hf., Haloferax; HMGCoA, 3-hydroxy-3-methylglutaryl coenzyme A; ISH, halobacterial insertion element; kb, kilobase(s) or 1000 bp; L33-pE191, H. halobium strain L33 with plasmid pE191 integrated into its genome (see section b and Fig. 1); Mev, mevinolin; nm, nanometer; nt, nucleotide(s); ori, origin of DNA replication, p, plasmid; PCR, polymerase chain reaction; PEG, polyethylene glycol; ${ }^{\mathrm{R}}$, resistance/ resistant; REG, regeneration; SDS, sodium dodecyl sulfate; wt, wild type. otic world, this motif occurs only in the branch of archaebacteria. The most abundant and well-studied member of the archaebacterial seven-helix protein family is $\mathrm{BR}$ which in the archaebacterium $H$. halobium enables photophosphorylation by light-driven proton pumping (Oesterhelt and Stoeckenius, 1973). In virtue of its thermo- and photochemical properties, BR provides a biological material of great interest for technical applications (Oesterhelt et al., 1991) and represents also a conserved structural framework which may be favourable for the engineering of membrane structures with variable functions.

The structure-function studies performed so far on BR have relied on either the generation and selection of modified BRs after in vivo random mutagenesis (Soppa and Oesterhelt, 1989) or the expression of site-directed mu- 
tants in E. coli (Khorana, 1988). The transformation system for halobacteria developed by Cline et al. (1989) permits the reintroduction and expression of $b o p$ in its homologous host, as reported by $\mathrm{Ni}$ et al. (1990). The BR negative phenotype of the $H$. halobium strains available as recipients for bop expression is a result of the inactivation of the chromosomal copy of bop by an insertion element (DasSarma et al., 1983). These strains therefore still carry the entire endogenous bop sequence, albeit interrupted, with the potential to undergo homologous recombination with the copy of bop borne on a plasmid. A reliable bop expression system in these strains may be based either on a stable self-replicating bop expression vector or on a specific recombination event of the cloned bop sequences into the genome. A bop expression vector, which was derived from a plasmid isolated from Halohacterium $\mathrm{sp}$. GRB, failed to produce wt amounts of BR due to plasmid instability (Krebs et al., 1991).

In this work we attempted to develop a homologous bop expression system at wt level by means of site-specific vector integration. Homologous recombination has been successfully exploited in several organisms as a tool for the analysis of gene expression (Vasseghi and Claverys, 1983; Orr-Weaver et al., 1983; Capecchi, 1989; Gal et al., 1991). The aim of the present study was to document the occurrence of homologous recombination between newly added exogenous DNA and chromosomal sequences in an archaebacterial strain and to propose a model which elucidates the mechanism of vector integration into the halobacterial genome. Furthermore, the exact mapping of the recombination locus yields information concerning the influence of upstream regions on the expression of bop. Finally, the system we studied should be suitable for the effective production and expression of bop mutants.

\section{RESULTS AND DISCUSSION}

\section{(a) Construction of an Escherichia coli-Halobacterium halobium shuttle expression vector}

For the development of a bop expression system for $H$. halobium we utilized the $H f$. volcanii-E. coli shuttle vector pWLI02 $\triangle B A$ which is a derivative plasmid of pWL102 (Lam and Doolittle, 1989). This plasmid has an ori derived from $H f$. volcanii and is stable in the restriction minus $H$. halobium strain $\mathrm{PO}_{3}$ after transformation (Blaseio and Pfeifer, 1990).

The construction of the bop expression vector pEF 191 is outlined in Fig. 1. It is a phasmid vector which contains both an $E$. coli and a halobacterial ori together with the $A p^{R}$ and $\mathrm{Mev}^{\mathbf{R}}$ markers and therefore may be propagated and selected for in both organisms. The presence of the intergenic region from the phage $\mathrm{fl}$ allows for the isola-

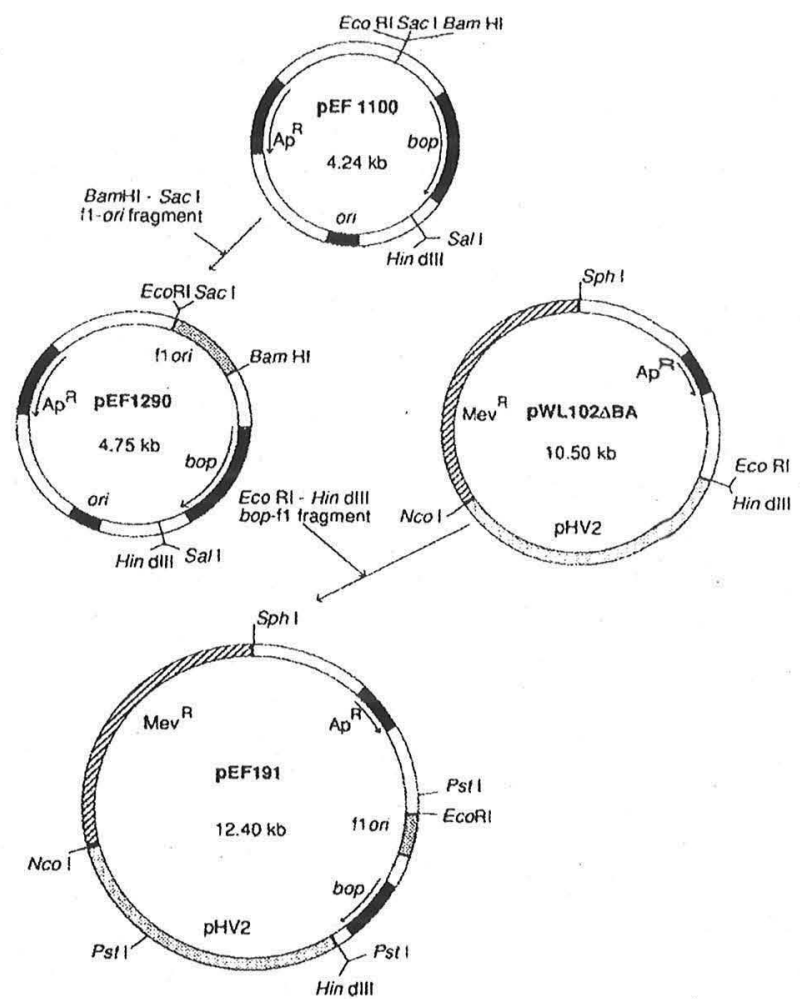

Fig. 1. Construction of the hop expression and mutagenesis vector pEF191. The starting plasmid pEF1100 carries a 1.4-kb genomic fragment which comprises bop and 388 bp upstream from the start codon and 200 bp downstream from the stop codon. The 0.5-kb BamHI-Sac] fragment bearing the $\mathrm{fl}$ ori was isolated from the plasmid pUCfl (Pharmacia). This fragment was cloned into pEF1100 DNA, resulting in the vector pEF 1290. The final construct, pEF 191, was obtained by excising the $1.9-\mathrm{kb}$ bop-f 1 fragment from $\mathrm{pEF} 1290$ with EcoRI +HIindIII and ligating it into pWLI02 $\triangle B A$ DNA which had been digested with the same enzymes. pWL102 $\triangle B A$ is a derivative plasmid of the E.coliIIf.volcanii shuttle vector PWL102 (Lam and Doolittle, 1989), which is missing the IIindIII site between the halobacterial ori and the $\mathrm{Mev}^{\mathrm{R}}$. The $p$ WL102 $\triangle B A$ plasmid DNA was a kind gift of M. Mevarech. Methods: Transformation of $H$. halohium with plasmid DNA was performed following the procedure described by Cline et al. (1989) with some minor modifications: after treatment with PEG600, spheroplasts were diluted with $9.5 \mathrm{ml}$ REG solution $\left(3.5 \mathrm{M} \mathrm{NaCl} / 1.50 \mathrm{mM} \mathrm{MgSO} \cdot 7 \mathrm{H}_{2} 0.50 \mathrm{mM}\right.$ $\mathrm{KCl} / 7 \mathrm{~m} \mathrm{M} \mathrm{CaCl} ; 50 \mathrm{mM}$ Tris. $\mathrm{HCl} \mathrm{pH} 7.2 ; 15 \%$ sucrose), pelleted and resuspended in $1 \mathrm{ml} \mathrm{H}$. halohium complex liquid medium as described (Cline et al., 1989). After $12 \mathrm{~h}$ of gentle shaking at $37 \mathrm{C}$, aliquots of $50 \% 100 \mu \mathrm{l}$ were spread on complex support medium containing 25 $\mu \mathrm{M}$ Mev.

tion of pEF 191 as single-stranded DNA, enabling sitedirected mutagenesis as well as sequencing without any further cloning steps.

The BamHI-Sal I genomic DNA fragment from $H$, halobium contained in pEF 191 comprises bop and short flanking sequences, 388 bp upstream from the start codon and $200 \mathrm{bp}$ downstream from the stop codon. In the noncoding regions, putative control elements for transcription and translation have been localized by comparison 
with halobacterial consensus sequences (Brown et al., 1989).

\section{(b) Transformation of Halobacterium halobium with the bop-expression vector $\mathrm{pEF} 191$}

In the BR-deficient $H$. halobium strain L33 the chromosomal copy of bop is inactivated by the stable insertion of the 520-bp long ISH 2 element (DasSarma et al., 1983). When L33 was transformed with pEF191 DNA isolated from E. coli, $10^{3} \mathrm{Mev}^{\mathbf{R}}$ transformants per $\mu \mathrm{g}$ of DNA were obtained (details of the transformation procedure are described in the legend to Fig. 1). Due to BR production $50-70 \%$ of these colonies were purple in colour. The high background of BR-negative transformants which were able to grow on Mev-containing medium may be due to a partial incorporation of the plasmid DNA with the concomitant rescue of the $\mathrm{Mev}^{\mathrm{R}}$ gene. This has been described previously for the transformation of a restriction-positive $H f$. volcanii strain with $E$. coli-derived pWL102 DNA (Blaseio and Pfeifer, 1990). The spontaneous occurrence of $\mathrm{Mev}^{\mathrm{R}}$ halobacteria was comparatively low, $1-5 \%$ as judged by the outcome of mock transformations.

Colony hybridization revealed that $>90 \%$ of the $\mathrm{Mev}^{\mathrm{R}}$ L33 transformants, which expressed bop, had also retained the E. coli portion of the vector. We analysed four of these clones by Southern analysis and found that none of them contained the plasmid in its self-replicating form. In three of the analysed transformants, the plasmid DNA had been inserted into the genome at the homologous bop locus. In the fourth isolate, integration had occurred at a nonhomologous site and therefore was not characterized further. Integrative transformation in $H$. halobium has also been detected with other pEF191-derived plasmids carrying mutant bop as well as the sensory rhodopsin I-encoding gene and hybrid halobacterial genes (E. F. and D. O., manuscript in preparation). No transformants expressing these genes were found in which the plasmid was present as an extrachromosomal element. Integration into the genome may be induced by linear DNA molecules which could arise by restriction of the $E$. coliderived plasmid DNA in L.33. This may be due to a restriction function present in L33 cells but absent in the restriction-minus $H$. halobium strain in which stable replication of pWL102 has been demonstrated (Blaseio and Pfeifer, 1990).

Fig. 2A illustrates the proposed mechanism of homologous recombination occurring between the plasmid and the chromosomal bop. According to this model integration of the plasmid is the result of a single cross-over event, which may occur on either side of the ISH2. This construction results in a duplication of the identical sequences and restores one wt copy of the gene. This recom- bination mechanism has been confirmed by Southern analysis. Fig. 2B and $C$ show the result of the analysis of two L33-pEF191 transformants, L33-pEF191/1 and L33pEF191/2, which had integrated the plasmid on different sides of the insertion element. In the third isolate identified, which is not shown in the figure, the side of integration was identical to that of L33-pEF 191/2. Total DNA isolated from L33 pEF191/1 and -/2 was cut with HindIII and PstI and hybridized after a Southern transfer with a labeled bop DNA fragment (Fig. 2B). Cleavage of the DNA isolated from the transformants as well as from untransformed cells with HindIII produced a smear in the high-molecular-weight range, which is due to the low cutting frequency of this enzyme in the halobacterial genome. The linearized vector, which has a size of $12.4 \mathrm{~kb}$, was not visible after hybridization in the HindIII-cleaved DNA from the transformed L33-pEF 191/1 and $-/ 2$ cells, indicating that the plasmid had integrated into the chromosome.

Pst I cuts the plasmid pEF191 into three fragments of $2.36,2.67$ and $7.37 \mathrm{~kb}$, with the $2.67-\mathrm{kb}$ fragment containing bop. In the DNA isolated from the transformants and cleaved with Pst I, two fragments were identified which hybridized with the bop sequence. The sizes of these fragments did not correspond to either the plasmid fragment or the L33 genomic bop fragment, indicating that homologous recombination into the chromosome had occurred at the bop locus. The PstI digest allowed the determination of the side of the insertion element on which the integration had taken place: the L33-pEF191/2 transformant yielded DNA fragments of $3.45 \mathrm{~kb}$ and $4.86 \mathrm{~kb}$, which resulted from homologous recombination upstream from the ISH2 element. Insertion downstream from the ISH2 element produced DNA fragments of 3.98 and $4.33 \mathrm{~kb}$ appearing as a doublet in the Pst I-digested DNA of L33-pEF191/1. Loss of the insertion element would reduce the size of one of the Pst I fragments in each transformant by $520 \mathrm{bp}$. This was not observed for either isolate. The comparison of Pst I-digested DNA from L 33 with that from the bop wt strain $R_{1} M_{1}$ confirms that the increase in size caused by the ISH2 integration can be well resolved, as is shown in Fig. 2B.

The mechanism of recombination depicted in Fig. 2A was confirmed by reprobing the Southern blot with labeled E. coli plasmid sequences (Fig. 2C). Besides the $4.33-\mathrm{kb}$ fragment in L33-pEF191/I and the 4.86-kb fragment in L33-pEF191/2 bearing bop, an additional band at $7.37 \mathrm{~kb}$ was detected in the transformants' DNA. This fragment corresponds to the plasmid fragment carrying $\mathrm{Mev}^{\mathrm{R}}$, the halobacterial ori as well as the complete $E$. coli plasmid sequence. This further supports the evidence that the identified transformants have incorporated the full length plasmid DNA by insertion at the chromosomal 
A

L $33: \quad 5.63 \mathrm{~kb}$
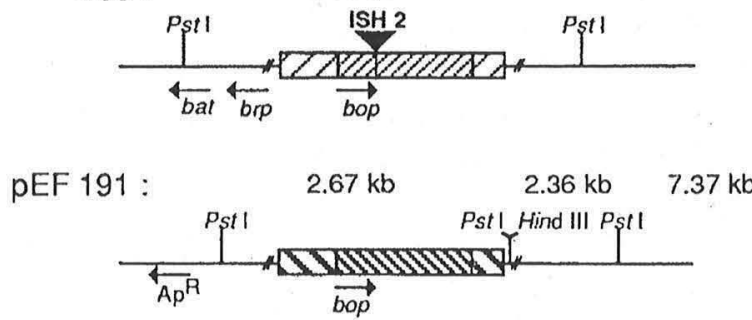

1:

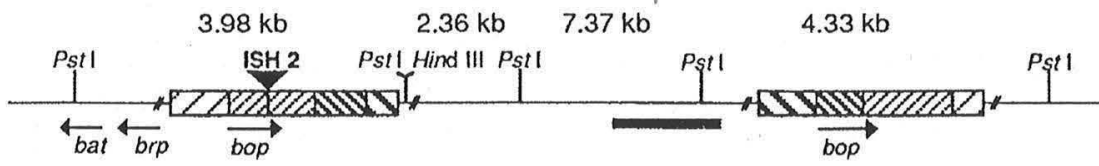

2:

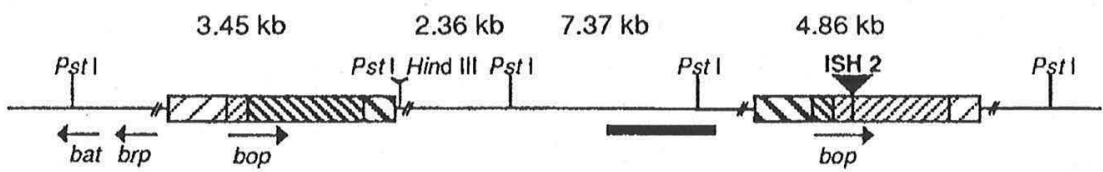

B L33 R1M1(wt) L33-pEF191/1 pEF191 L.33-pEF191/2 $\left|\begin{array}{lllllllllllllllllllllll}H & P & H_{+} P & H & P & H_{+} P & H & P & H_{+} P & P & H & H & P & H_{+} P\end{array}\right|$

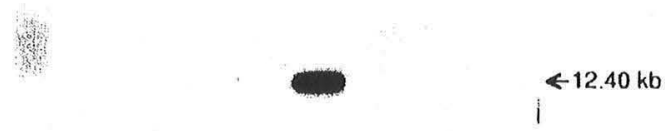

$5.10 \mathrm{kbm}$

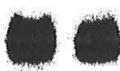

$\leftarrow 4.86 \mathrm{~kb}$

$3.38 \mathrm{~kg}=$

$\leftarrow 3.45 \mathrm{~kb}$

$\ll 2.67 \mathrm{~kb}$

C

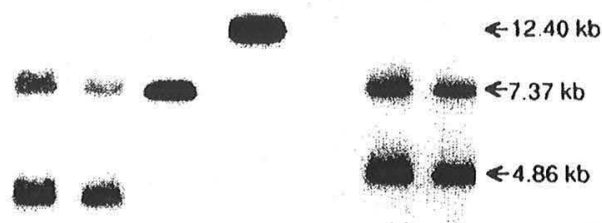


bop locus. Integration occurred at one copy per chromosome, as determined by comparing the intensity of the hybridization signals from the DNA of the transformants with that of different molar amounts of digested plasmid (not shown). Internal crossover between the two copies of bop on the chromosome did not impair the stability of the genotype of the transformants after 12 months of continuous passage.

\section{(c) Synthesis of BR in L33 cells transformed with pEF 191}

The ability to assay BR in the L33 transformants allowed us to investigate whether bop expression is dependent upon a defined upstream location of the regulatory genes bat and brp. Analysis of spontaneous bop mutants has demonstrated that bat and brp are involved in bop expression (Betlach et al., 1989), although nothing is known about the mechanism of interaction between these genes or their gene products. Since a cis-acting influence of the bat or brp sequence could not be excluded, Ni et al. (1990) developed a halobacterial bop expression vector which carried the entire bop cluster, with the exception of the last $43 \mathrm{bp}$ distal to bat. This plasmid is the only construct currently available which produced wt levels of BR in $H$. halobium, but the state of the plasmid in transformed cells had not been investigated.

According to the recombination scheme depicted above, two different genomic configurations are obtained depending on the integration locus of the plasmid. If integration occurs upstream from the ISH2 element, the wt bop cluster with the functional bop and the bat and brp in their native arrangement is restored. This has occurred in the transformant L33-pEF 191/2. In the isolate L33pEF 191/1, which has the plasmid inserted downstream from the ISH 2 element, the expression of bop is driven by the promoter region provided on the plasmid pEF191. This region comprises only $388 \mathrm{bp}$ upstream from the start codon. In this transformant, bat and brp are separated from the putative bop promoter by more than $10 \mathrm{~kb}$, compared with $0.5 \mathrm{~kb}$ in the wt. In both transformants the second copy of the gene present on the chromosome remains inactivated by the insertion element ISH 2 .

We examined the level of bop expression of the two transformants L33-pEF191/1 and $-/ 2$ and compared it with the bop wt strain $R_{1} M_{1}$. Northern analysis demonstrates that the bop specific mRNA is synthesized at the same level in the wt $\left(R_{1} M_{1}\right)$, the reconstituted (L33pEF191/2) and the interrupted (L33-pEF191/1) bop cluster, whereas in the $\mathrm{L} 33$ recipient strain no bop mRNA is detectable (Fig. 3).

Purple membrane isolated from the transformants displayed the same absorption maximum and the same bouyant density on sucrose gradients as material isolated from the wt (Fig. 4 and data not shown). The amount of $\mathrm{BR}$ isolated from both transformants was $60-70 \mathrm{nmol}$ per mg of total protein, and this value corresponded to the average amount that was produced by the wt.

These results demonstrate that the function of the bop promoter is independent of its location relative to the regulatory bat and brp sequences. These data are in agreement with the proposed regulation of bop via the gene products of brp and bat. The specific brp and bat mRNA transcripts have been determined under different conditions of growth, and a model for the function of these putative proteins has been proposed (Shand and Betlach, 1991).

The promoter region of bop has been defined by the determination of the transcription start point (Dunn et al., 1981) and the identification of adjacent conserved sequences (Thomm and Wich, 1988; Reiter et al. 1990). As BR synthesis in the transformant L33-pEF191/1 demonstrates, the 388-bp sequence upstream from the bop start codon contained in the plasmid pEF191 is sufficient

Fig. 2. Analysis of the homologous recombination. (A) Recombination between the homologous bop sequences on the plasmid (pEF191) and on the chromosome (L33) result in integration of the plasmid and duplication of the homologous DNA. Depending on the location of the integration point relative to the insertion element ISH2, contained in the chromosome of the recipient strain $\mathbf{L} 33$, two different configurations are obtained. Integration downstream from ISH2 results in configuration I, upstream from ISH2 in configuration 2. The locations of the Pstl and HindIII resiriction sites on the plasmid and the chromosome are indicated, as well as the size of the fragments that will arise after digestion of the depicted DNAs with these restriction endonucleases. The regions of homology on the chromosome and on the plasmid are indicated by variously hatched boxes. The pBR322 fragment used for Southern blot analysis is indicated by a black bar. The figure is not drawn to scale. (Panel B) Southern blot analysis of chromosomal DNA isolated from two independent transformants, L33-pEF191/L and L33-pEF191/2, using the 1.4-kb BamHI-Sall fragment of pEFII00 as a bopspecific probe. DNA from the untransformed recipient strain $\mathrm{L} 33$, from the bop wt strain $\mathrm{R}_{1} \mathrm{M}_{1}$, as well as an equimolar amount of pEF 191 plasmid DNA were also analyzed. (Panel C) Rehybridization of the blot shown in panel $\mathbf{B}$ with pBR322 DNA. Methods: Isolation of total halobacterial DNA was performed as described by Vogelsang et al. (1983). After electrophoresis on an 1\% agarose gel the DNA was transferred to a nitrocellulose membrane by capillary blotting (Sambrook et al., 1989) and hybridized with ${ }^{32}$ P-labeled DNA fragments. Labeling of the DNA fragments was performed with the Random Primed DNA Labeling Kit from Boehringer Mannheim following the instructions of the manufacturer. Hybridization conditions were as follows: $0.1 \% \mathrm{SDS} / 5 \times$ Denhardt's solution $/ 2.5 \times \mathrm{SSC} / 40 \%$ formamide $/ 200 \mu \mathrm{g}$ of sonified hering sperm DNA per ml hybridization solution and $1-2 \times 10^{4} \mathrm{cpm}$ of the radioactive probe per $\mathrm{cm}^{2}$ of membrane. After incubation at $40^{2} \mathrm{C}$ for $12-24 \mathrm{~h}$, the filters were submitted to the following 15 -min washes: $0.1 \% \mathrm{SDS} / 5 \times$ Denhardt's solution $/ 2.5 \times \mathrm{SSC} / 40 \%$ formamide at $40^{\circ} \mathrm{C} ; 2.5 \times \mathrm{SSC} / 40 \%$ formamide at $400^{\circ} \mathrm{C} ; 2.5 \times \mathrm{SSC}$ at room temperature. For the determination of the size of the labeled fragments on the Southern blots, the EtdBr-stained $1 \%$ agarose gel on which a molecular weight standard had been separated was photographed before being processed for blotting, and a print of the stained pattern was matched to the exact size of the nitrocellulose sheet and corresponding autoradiogram. 
A

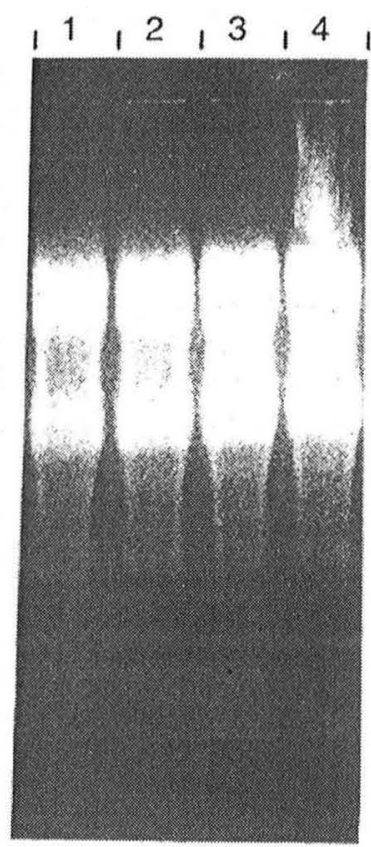

B

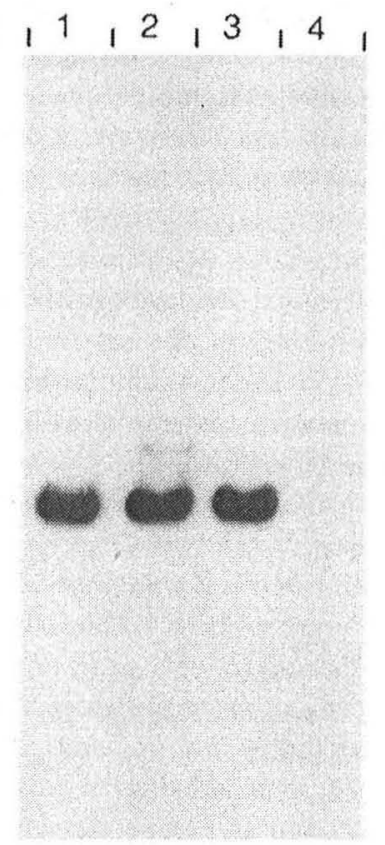

Fig. 3. Northern blot analysis of transcripts isolated from L.33 cells transformed with pEF191. Total halobacterial RNA was isolated according to the procedure of Chomczynski and Sacchi (1987). Equal amounts of total RNA from L33-pEF191/2 (lane 1), L33-pEF191/1 (lane 2), $R, M_{1}$ (lane 3), and L33 (lane 4), cells were electrophoresed through a $2.2 \mathrm{M}$ formaldehyde- $1 \%$ agarose gel (A), transferred to nitrocellulose and probed with a I.4-kb DNA fragment bearing bop (B) as described in the legend to Fig. 2.

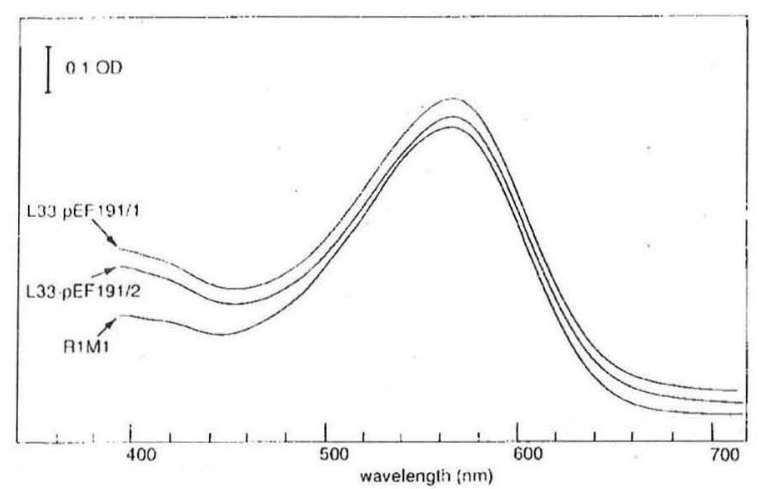

Fig. 4. Visible spectra of BR in membranes of transformed L.33 cells and $R_{1} M_{1}$ wt cells. The arbitrary baseline was offset for clarity. Methods: The 700-ml cultures of L33 cells transformed with the hop expression vector pEF 191 and of $R, M_{1}$ wt cells were grown, harvested and dialyzed against distilled water overnight as described previously (Oesterhelt and Stoeckenius, 1974). Absorption spectra were recorded at room temperature in $10 \mathrm{mM}$ Na.phosphate buffer at $\mathrm{pH} 7.0$ using an Aminco DW2000 spectrophotometer. The amount of BR contained in the membrane preparation analysed was calculated from the absorption peak at $568 \mathrm{~nm}$ using $\varepsilon_{508 \mathrm{~nm}}=63000 \mathrm{M}^{-1} \mathrm{~cm}^{-1}$. The amount of total protein in the membrane preparations was determined with the BCA protein assay reagent following the protocol provided by Pierce.

for the expression of bop. This provides the first genetic approach to defining the limits of the bop promoter sequence in vivo. In the absence of a stable self-replicating bop expression vector for $H$. halobium, the site-specific integration described here may be further utilized to verify the putative transcription and translation signals of bop.

\section{(d) Utilization of pEF191 for the construction and expression of BR mutants}

The system we describe has also been used for the production and expression of site-directed bop mutants. Details about the mutant proteins will be given in a subsequent paper (U.S. and D.O., manuscript in preparation). The efficiency of mutagenesis using the procedure of Kunkel et al. (1987) varied between $40 \%$ and $60 \%$ depending on the number and on the location of the mutated positions. The mutations we have introduced affected the absorption behaviour of the pigment, and the halobacterial colonies expressing the mutated bop could be distinguished from those in which vector in tegration had restored the wt gene by colour selection. The frequency with which transformants expressing the wt gene were obtained was not systematically determined but was dependent on the location of the mutation relative to the ISH2 in the genomic copy of the gene. The genomic configuration as well as the presence of the desired mutation on the chromosomal DNA of the transformants can also be easily established by PCR techniques.

The absorption spectrum of a mutated BR obtained with the pEF191 vector is shown in Fig. S. In this mutant (D85T) the $\mathrm{Asp}^{85}$ has been changed to a Thr, which results in a $19-\mathrm{nm}$ red shift of the absorption maximum. Since this mutation is located only $50 \mathrm{bp}$ downstream from the position of ISH2 on the chromosome, the geno-

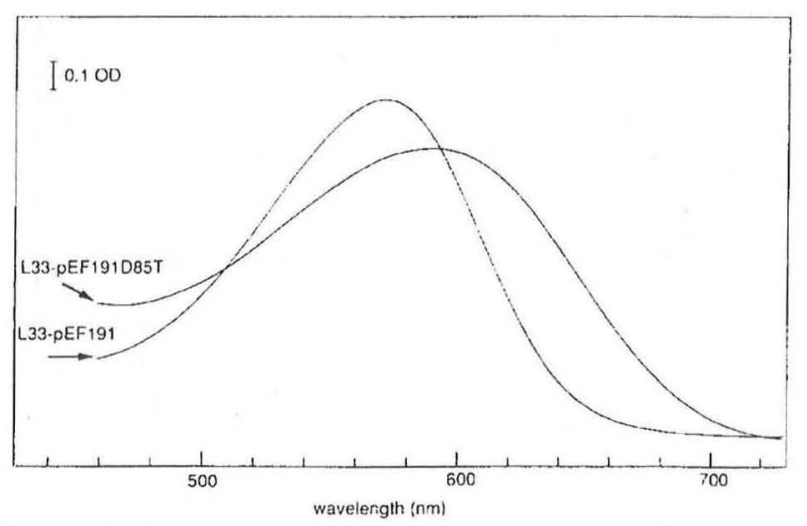

Fig. 5. Visible spectra of L33 cells transformed with pEF191 bearing the wt and a mutated bop. In the mutant BR (L33-pEF191 D85T), Asp ${ }^{85}$ has been changed to Thr. This resulted in a red shift of the absorption maximum of $19 \mathrm{~nm}$. The spectra were recorded under the same conditions as described in the legend to Fig. 4. 
mic arrangement in which the wt gene is restored and the mutated gene is inactivated by the ISH 2 requires that the strand break leading to vector integration occur within this 50 -bp sequence between the mutation and ISH2. The probability of this event is low compared with recombination over the whole 780 -bp region of homology. In the transformation experiment performed with this plasmid, restoration of the wt phenotype was not observed, confirming this assumption.

In order to exploit halobacteria as a novel expression system, further tailoring of the vector pEF191 will be performed, which will facilitate the cloning and expression of other genes coding for seven transmembrane helical proteins and for other retinal proteins in particular.

Note: As this paper was submitted for review, a paper by Mankin et al. (1992) was pubiished, which reports on the mutagenesis of the 23S RNA gene of $H$. halobium via homologous recombination of plasmid sequences into the genome.

\section{ACKNOWLEDGEMENTS}

We wish to thank T. May and F. Pfeifer for very valuable discussions and W. Havelka and M. Maniak for critical reading of the manuscript.

\section{REFERENCES}

Betlach, M.C., Shand, R.F. and Leong, D.M.: Regulation of the bacterio-opsin gene of a halophilic archaebacterium. Can. J. Microbiol. 35 (1989) 134-140.

Blaseio, U. and Pfeifer, F.: Transformation of Halobacterium halobium: development of vectors and investigation of gas vesicle synthesis. Proc. Natl. Acad. Sci. USA 87 (1990) 6772-6776.

Brown, J.W., Daniels, C.J. and Reeve, J.N.: Gene structure, organization, and expression in archaebacteria. CRC Crit, Rev. Microbiol. 16 (1989) 287-335.

Capecchi, M.R.: The new mouse genetics: altering the genome by gene targeting. Trends Genet. 5 (1989) 70-76.

Chomczynski, P. and Sacchi, N.: Single-step method of RNA isolation by acid guanidinium thiocyanate-phenol-chloroform extraction. Analyt. Biochem. 162 (1987) 156-159.

Cline, S.W., Lam, W.L., Charlebois, R.L., Schalkwyk, L.C. and Doolittle, W.F.: Transformation methods for halophilic archaebacteria. Can. J. Microbiol. 35 (1989) 148-152.

DasSarma, S., RajBhandary, U.L. and Khorana, H.G.: High frequency spontaneous mutation in the bacterio-opsin gene in Halobacterium halobium is mediated by transposable elements. Proc. Natl. Acad. Sci. USA 80 (1983) 2201-2205.

Dunn, R., McCoy, J., Simsek, M., Majumdar, A., Chang, S.H., RajBhan- dary, U.L. and Khorana, H.G.: The bacteriorhodopsin gene. Proc Natl. Acad. Sci. USA 78 (1981) 6744-6748.

Gal, S., Pisan, B., Hohn, T., Grimsley, N. and Hohn, B.: Genomic homologous recombination in planta. EMBO J. 10 (1991) $1571-1578$.

Khorana, H.G.: Bacteriorhodopsin, a membrane protein that uses light to translocate protons. J. Biol. Chem. 263 (1988) 7349-7352.

Krebs, M.P., Hauss, T., Heyn, M.P., RajBhandary, U.L. and Khorana, H.G.: Expression of the bacteriorhodopsin gene in Halohacterium halobium using a multicopy plasmid. Proc. Natl. Acad. Sci. USA 88 (1991) 859-863.

Kunkel, T., Roberts, J.D. and Zakour, R.A.: Rapid and efficient sitespecific mutagenesis without phenotypic selection. Methods Enzymol. I 54 (1987) 367-382.

Lam, W.L. and Doolittle, W.F.: Shuttle vectors for the archaebacterium Halobacterium volcanii. Proc. Natl. Acad. Sci. USA 86 (1989) 5478-5482.

Mankin, A.S., Zyrianova, I.M., Kagramanova, V.K. and Garrett, R.A. Introducing mutations into the single-copy chromosomal 23S rRNA gene of the archeon Halobacterium halobium by using an rRNA operon-based transformation system. Proc. Natl. Acad. Sci. USA 89 (1992) 6535-6539.

Ni, B., Chang, M., Duschl, A., Lanyi, J. and Needleman, R.: An efficient system for the synthesis of bacteriorhodopsin in H. halobium. Gene 90 (1990) 169-172.

Oesterhelt, D. and Stoeckenius, W.: Functions of a new photoreceptor membrane. Proc. Natl. Acad. Sci. USA 70 (1973) 2853-2857.

Oesterhelt, D. and Stoeckenius, W.: Isolation of the cell membrane of Halobacterium halobium and its fractionation into red and purple membrane. Methods Enzymol. 31 (1974) 667-686.

Oesterhelt, D., Bräuchle, C. and Hampp, N.: Bacteriorhodopsin: a biological material for information processing. Q. Rev. Biophys. 24 (1991) 425-478.

Orr-Weaver, T.L., Szostak, J.W. and Rothstein, R.J.: Genetic applications of yeast transformation with linear and gapped plasmids. Methods Enzymol. 101 (1983) 228-252.

Reiter, W.-D., Hüdepohl, U. and Zillig. W.: Mutational analysis of an archaebacterial promoter: essential role of a TATA box for transcription efficiency and start-site selection in vitro. Proc. Nat1. Acad. Sci. USA 87 (1990) 9509-9513.

Sambrook, J., Fritsch, E.F. and Maniatis, T.: Molecular Cloning: A Laboratory Manual, 2nd ed. Cold Spring Harbor Laboratory Press, Cold Spring Harbor, NY, 1989.

Shand, R.F. and Betlach, M.C.: Expression of the bop gene cluster of Halobacterium halobium is induced by low oxygen tension and by light. J. Bacteriol. 173 (1991) 4692-4699.

Soppa, J. and Oesterhelt, D.: Bacteriorhodopsin mutants of Halobacterium spec. GRB, I. The S-bromo-2'-desoxyuridine-selection as a method to isolate point mutants in halobacteria. J. Biol. Chem. 264 (1989) 13043-13048

Thomm, M. and Wich, G.: An archaebacterial promoter element for stable RNA genes with homology to the TATA box of higher eukaryotes. Nucleic Acids Res. 16 (1988) 151-163.

Vasseghi, H. and Claverys, J.-P.: Amplification of a chimeric plasmid carrying an erythromycin-resistance determinant introduced into the genome of Streptococcus pneumoniae. Gene 21 (1983) 285-295.

Vogelsang, H., Oertel, W. and Oesterhelt., D.: Isolation of the bacteriorhodopsin gene by colony hybridization. Methods Enzymol. 97 (1983) 226-241. 